\title{
Algae/bacteria consortium in high rate ponds: Influence of solar radiation on the phytoplankton community
}

\author{
Paula Peixoto Assemany *, Maria Lúcia Calijuri, Eduardo de Aguiar do Couto, \\ Mauro Henrique Batalha de Souza, Nirlane Cristiane Silva, Aníbal da Fonseca Santiago, \\ Jackeline de Siqueira Castro
}

Universidade Federal de Viçosa, Department of Civil Engineering, Núcleo de Pesquisas Ambientais Avançadas - nPA, Viçosa, MG, Brazil

\section{A R T I C L E IN F O}

\section{Article history:}

Received 2 October 2014

Received in revised form 12 January 2015

Accepted 17 January 2015

Available online 24 January 2015

\section{Keywords:}

Biological system

Multivariate statistic

Microalgae

Domestic sewage

\begin{abstract}
A B S T R A C T
Using multivariate statistical tools, the composition of the phytoplankton community was related to the characteristics of the domestic sewage used as culture medium in three high rate ponds (HRPs) submitted to different solar radiation levels. A total of 32 genera of phytoplankton were identified in the ponds; the class Chlorophyceae was the most abundant during the entire sampling period, with a larger number of individuals of the genus Desmodesmus in the summer and fall, and of the genus Chlorella in the winter and spring. The lowest occurrence of phytoplankton was observed in the fall, with behavior similar to the evolution of solar radiation throughout the year. Blocking over $30 \%$ of the solar radiation allowed for less variability of the phytoplankton community and favored the growth of biomass with higher density of individuals, as well as higher concentrations of chlorophyll- $a$ and dissolved oxygen. On the other hand, the pond with $80 \%$ of shading presented the lowest mean density of organisms; from the perspective of wastewater treatment, however, it can be considered the most efficient in terms of organic matter and nutrient removal. According to the regression analysis, the algal biomass in HRPs can be maximized mostly if we consider the positive effect of carbon and phosphorus and the limiting effect of nitrogen and non-biodegradable organic load. For the conditions evaluated in this study, the photoinhibition phenomenon was not observed. Other aspects such as competition with other microorganisms for space and nutrients, or predation by zooplankton, seemed to be more significant for the growth and development of algal biomass.
\end{abstract}

(c) 2015 Elsevier B.V. All rights reserved.

\section{Introduction}

Biological systems for wastewater treatment are usually controlled by operational variables, typically chemical or physical. Strategies to optimize such systems are usually regarded more as chemical than biological (Yuan and Blackall, 2002), compromising the development of the microorganisms responsible for degradation, and consequently affecting treatment efficiency.

High rate ponds (HRPs) are shallow, open ponds designed in a racetrack configuration, with continuous mixing provided by paddle-wheels (Oswald and Golueke, 1960). In open systems for

\footnotetext{
* Corresponding author. Tel.: +55 3138993098.

E-mail addresses: paula_assemany@hotmail.com (P.P. Assemany), lucia.calijuri@gmail.com (M.L. Calijuri), eduardo.acouto@hotmail.com (E.d.A.d. Couto), maurohbatalha@gmail.com (M.H.B.de Souza),nirlane.silva@ufv.br (N.C. Silva), anibalsantiago@gmail.com (A.d.F. Santiago),

jackelinesiqueiracastro@yahoo.com.br (J.d.S. Castro).
}

microalgae cultivation, especially those associated with wastewater treatment, the combination between microalgae and bacteria has been widely studied. Algal photosynthesis produces the oxygen required for degradation of organic matter by heterotrophic bacteria. Nutrients and the $\mathrm{CO}_{2}$ from oxidation are assimilated by the algae (Santiago et al., 2013). The production of microalgae in consortium with other microorganisms may represent an alternative for reducing the costs involved in the process of obtaining biofuels, since it presents competitive advantages such as less influence of environmental fluctuations and easier harvesting and processing of the biomass (Pires et al., 2013).

The characteristics of a HRP, such as the heavy load of mineral and organic pollution, combined with the shallow depth, intensify the strong daily and seasonal changes of the growth medium variables. The planktonic succession in HRPs can be considered similar to that in natural environments. The difference is that, depending on the characteristics of the effluent used as culture medium, the nutrients (nitrogen and phosphorus) are not limiting 
factors. The HRPs belong to the group of shallow hypereutrophic environments, and thus present some analogies with the functioning of a natural pond. Due to the permanent agitation and constant nutrient input, the HRP is very similar to a natural ecosystem, despite its reduced hydraulic retention time (HRT). The continuous agitation given by the paddlewheels submits the algae to fast cycles of vertical circulation, and consequently, luminosity: the cells frequently and rapidly pass through the clarity of the surface and the darkness of the bottom, which are translated into intense photosynthetic mechanisms and nutrient assimilation.

The most relevant variables to describe the dynamics of the phytoplankton are the ones directly related to the processes of the eutrophic or hypereutrophic medium. These variables are light intensity, temperature, nutrients and turbulence or mixture (Wium-Andersen et al., 2013). Directly involved in the photosynthetic mechanisms, the light intensity represents a primary factor for the development and multiplication of planktonic algae. As well as for vegetal organisms, there is a minimum light requirement for phytoplankton to perform photosynthesis. In a system fed with wastewater, the light frequently plays a limiting role, and the productivity is strongly related and dependent upon the amount of solar energy received (Cromar et al., 1996). It is well known that high light intensity for a considerable amount of time can be translated into a decrease in photosynthetic production (Chisti, 2007); however, on the other hand, it is believed that some algal species are highly capable of progressively adapting to the light intensity to which they are submitted, thus photoinhibition decreases or disappears in well adapted algae (Horne and Goldman, 1994). Moreover, for the specific case of the HRPs, since algae are temporarily submitted to strong light intensities due to turbulence, this inhibitory effect of solar radiation can be disregarded (Fernandes et al., 2014); however, the influence with respect to the composition of the community should not be neglected.

Despite its importance as a renewable energy source and the wide research on HRPs for wastewater treatment, the phytoplankton community in these systems is very little studied. There are few studies which exclusively address their interaction and behavior according to the characteristics of the culture medium and environmental variables (but see Barthel et al., 2008; Canovas et al., 1996; Park et al., 2011). Therefore, the objective of this study is to evaluate how solar radiation influences the phytoplankton community in HRPs. Using multivariate statistical tools, the composition of the phytoplankton community was associated with the characteristics of the domestic sewage used as culture medium in three HRPs submitted to different levels of solar radiation.

\section{Material and methods}

The experiment was carried out in Viçosa-MG, Brazil $\left(20^{\circ} 45^{\prime} 14^{\prime \prime} \mathrm{S}, 42^{\circ} 52^{\prime} 54^{\prime \prime} \mathrm{W}\right)$. The climate in Viçosa is Cwa (humid subtropical climate) according to the Köppen classification, the annual average temperature is $19.4{ }^{\circ} \mathrm{C}$, and the annual average relative humidity is $81 \%$. The annual average precipitation is $1221.4 \mathrm{~mm}$, concentrated in the period from November to March. The studied domestic sewage treatment system consisted of an upflow anaerobic sludge blanket (UASB) reactor followed by three HRPs.

In order to evaluate the influence of different solar radiation intensities in the biomass growth process, the HRPs were covered with screens that provided different shade levels. The first pond (HRP1) was the control unit without any cover, and the ponds 2 (HRP2) and 3 (HRP3) operated with screens that blocked $30 \%$ and $80 \%$ of the solar radiation, respectively. Fig. 1 illustrates the scheme of the experiment. The shading screens were made of high-density polyethylene, such as those used for agriculture crops, Sombrite ${ }^{\circledR}$ type 1003 and type 1008 , for ponds 2 and 3, respectively.

\subsection{Environmental and water quality variables}

Combined samples for the analysis of physical and chemical variables were carried out every $2 \mathrm{~h}$ (from $8 \mathrm{am}$ to $6 \mathrm{pm}$ ), on a weekly basis from January to November. Simple random samples for chlorophyll analyses were collected at 10:00 h. On sampling dates, the variables $\mathrm{pH}$, dissolved oxygen (DO), and temperature ( $T$ ) were measured at the site, every $2 \mathrm{~h}$, using the Hach HQ40d portable meter (Luminescent Dissolved Oxygen-LDO-for DO). The photosynthetically active radiation (PAR) $(400-700 \mathrm{~nm})$ was also measured on the water surface using the LI-COR LI-193 Underwater Spherical Quantum Sensor.

The physical-chemical analyses of influent and effluent wastewater were carried out according to the Standard Methods for the examination of water and wastewater (APHA, 2005): total and soluble chemical oxygen demand (CODt and CODs, respectively) (5220D), total suspended solids (TSS) (2540D), volatile suspended solids (VSS) $(2540 \mathrm{E})$, ammoniacal nitrogen $\left(\mathrm{N}-\mathrm{NH}_{4}{ }^{+}\right)$ (4500-NH3C), total kjeldahl nitrogen (TKN) (4500-NorgB), nitrate $\left(\mathrm{N}-\mathrm{NO}_{3}{ }^{-}\right)\left(4500-\mathrm{NO}_{3} \mathrm{~A}\right)$, total phosphorus (TP) (4500P D), soluble phosphorus (SP) (4500 PC). The dissolved organic carbon (DOC) and the dissolved inorganic carbon (DIC) were determined using the Shimadzu TOC 5000 analyzer. The chlorophyll- $a$ levels were determined by spectrophotometry according to APHA (2005), and the calculations were performed using equations described in the Nederlands Norm Nen 6520 (NEN, 1981)

\subsection{Composition of the phytoplankton community}

The samples for the characterization of the phytoplankton community were collected at a 2-week interval at each HRP from January to November. For qualitative analysis, the samples were collected using a $20-\mu \mathrm{m}$ mesh-size plankton net and immediately fixed with formaldehyde $4 \%(1: 1)$. The taxonomic identification was performed at the genera level using an inverted optical microscope (Olympus IX 70). The morphologic and morphometric characteristics of the vegetative and reproductive cycles of the relevant species (of significant taxonomic value) were analyzed according to the specialized literature (Bicudo and Menezes, 2006; Bourrelly, 1970; Parra et al., 1983).

For the quantitative analysis, 1-L effluent samples were collected in amber bottles and preserved in laboratory with Lugol's solution $5 \%$. After sedimentation, the supernatant was discarded and the remaining concentrate of approximately $100 \mathrm{~mL}$ was homogenized and $1 \mathrm{~mL}$ was transferred using a pipette to the

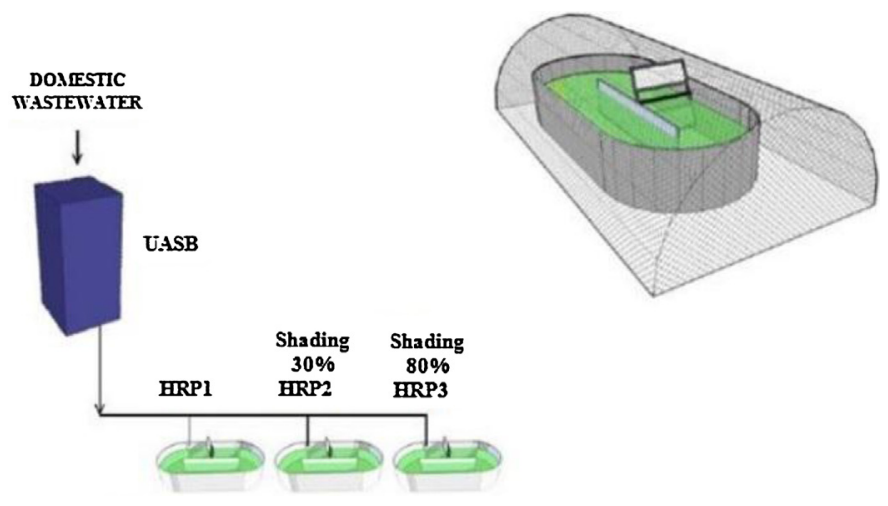

Fig. 1. Experiment scheme. 
Sedgwick-Rafter chamber. After $15 \mathrm{~min}$, the chamber was taken to the microscope with $400 \times$ magnification for counting.

\subsection{Statistical analyses}

Monitoring programs result in extensive and complex databases, covering several aspects which are difficult to analyze and interpret due to the interrelationship among the different variables (Huang et al., 2011). Given the complexity and dynamism of ecological interactions, especially in wastewater biological treatment systems, studies are increasingly searching for the aid of sophisticated techniques such as multivariate statistics (Balachandran et al., 2008). The multivariate statistics is one of the main tools to relate environmental variables and the density of phytoplankton populations (Thangaradjou et al., 2012).

The principal component analysis (PCA) was initially carried out to reduce the number of variables and facilitate the linear multiple regression analysis, as well as to assess the real contribution of each variable to the total variability of the data. For each pond we performed an individual analysis in order to observe the main water quality parameters that influence the dynamics of the HRP under different incident solar radiation intensities. The linear multiple regression analysis was performed using the variables selected by the PCA. The objective of the regression analysis was to verify the influence of physical and chemical variables, i.e., the quality of the culture medium, on the phytoplankton population (ind $\mathrm{mL}^{-1}$ ) in the ponds. The total phytoplankton biomass was considered as dependent variable; the physical and chemical parameters were considered as independent variables.

The statistical analyses were carried out using version 3.0.2 of the R statistical software (Development Core Team R, 2013). The multivariate statistical procedures used the FactoMineR module provided by the R software for the PCA analysis.

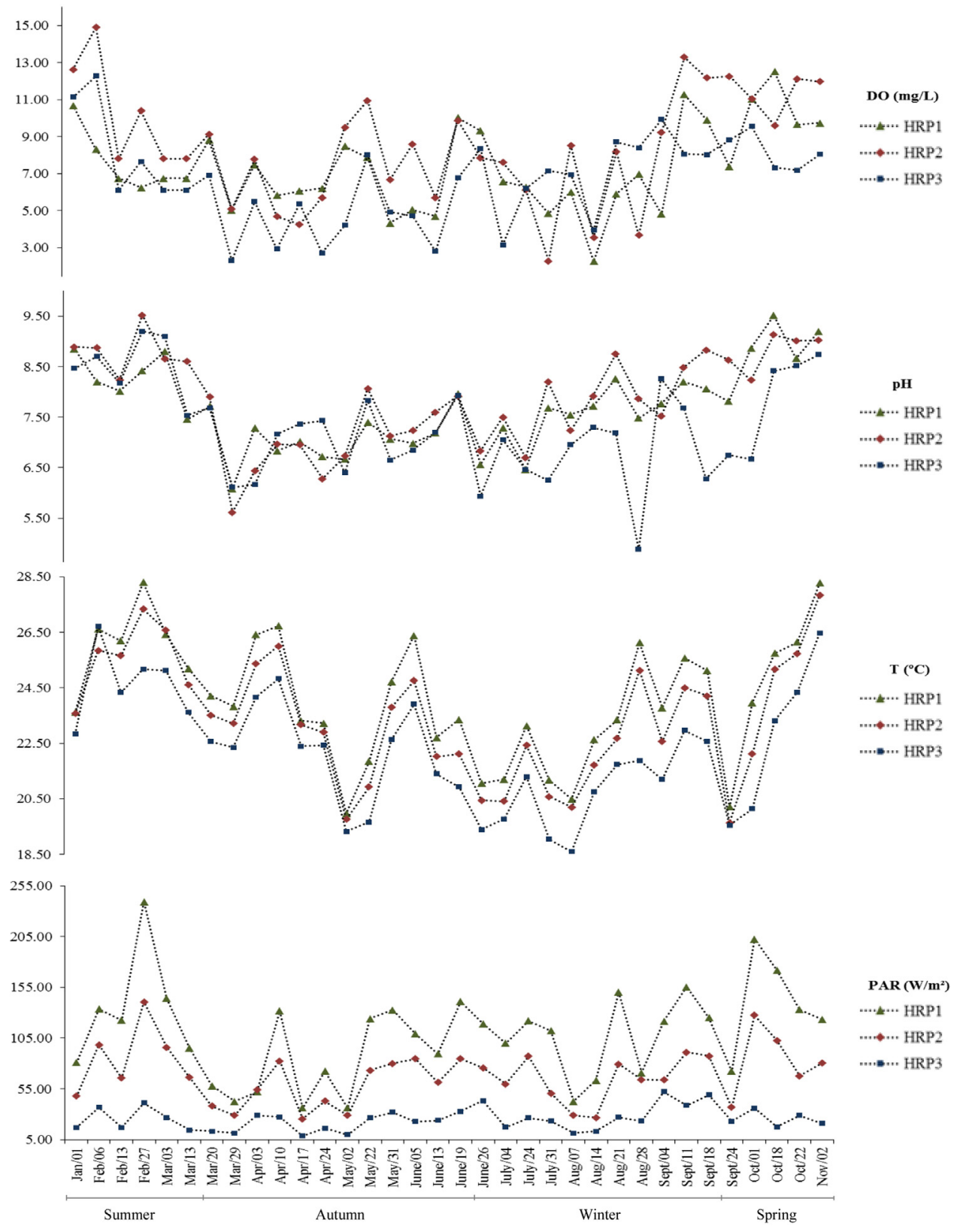

Fig. 2. Environmental variables of the high rate ponds throughout the sampling period. 


\section{Results and discussion}

\subsection{Environmental variables}

The environmental variables are shown in Fig. 2.

The HRP1 presented the highest PAR mean value due to the absence of the shading screen; as expected, the PAR levels decreased with the increase in the percentage of radiation blocked by the screens. We highlight the fall as the season with the lowest PAR values. The PAR variations throughout the year were smooth, representing little differentiation among the seasons in the region. Specifically in Brazil, the winter can present very high light incidence due to the little cloudiness in this season, with brighter and sunnier days when compared with the summer, for instance.

As shown for the PAR, in the ponds submitted to higher light intensities, higher temperatures were observed. The variables $\mathrm{pH}$ and DO had similar behavior, with higher DO mean values observed in the HRP2, which probably indicates greater photosynthetic activity, and consequently, lower $\mathrm{CO}_{2}$ concentrations, leading to an increase in $\mathrm{pH}$. The opposite can be stated for the HRP3, which presented lower $\mathrm{pH}$ values due to the lower photosynthetic activity, presenting better conditions to heterotrophic bacteria activity. The highest $\mathrm{pH}$ value of 9.5 was measured in the HRP2 in the summer and HRP1 in the spring. According to Park and Craggs (2011), pH values until 8.0 allow the continued growth of heterotrophic bacteria. Oswald (1988) highlighted that one of the consequences of the continuous mixing of the liquid in HRPs is to ensure less diurnal variation of the $\mathrm{pH}$, and therefore, better condition for biological oxidation in these environments. Low DO values (below $5 \mathrm{mg} \mathrm{L}^{-1}$ ) were observed in the HRP3, mainly in the fall and winter. In the spring, DO values for all three ponds were higher than the saturation level. The $\mathrm{pH}$ and DO variables showed a clear tendency and followed the behavior of solar radiation, i.e., their values increased in the spring and summer and decreased in the fall and winter, which highlights the importance of solar radiation for the dynamics of HRPs.

\subsection{Composition of the culture medium}

Table 1 presents the characterization of the HRPs influent and culture medium.

It is important to notice that large deviations, as the ones found in this study, are quite common for environmental variables, mainly those in an uncontrolled situation with the influence of many aspects and climate conditions.

The HRPs 1 and 2 presented algae biomass amounts statistically higher than that obtained in the HRP3. We can state that blocking $80 \%$ of the solar radiation inhibited the growth of algal biomass since under low radiation levels, this biomass did not have enough energy to supply its growth needs. This fact also reinforces the importance of solar radiation in HRPs dynamics. For Oswald (1988), more than $90 \%$ of the incident solar radiation is converted into heat and at most $10 \%$ is converted into chemical energy. Therefore, solar radiation is a key factor for photosynthetic activity in these systems (Park and Craggs, 2011).

An inversely proportional relationship between the amount of autotrophic organisms (represented by the chlorophyll-a) and VSS was observed in the ponds, which reflects the competition between algae and bacteria for space and nutrients. The VSS/chlorophyll- $a$ ratio was higher in the HRP3, suggesting a greater proportion of non-algal biomass in this pond, compared with the others. However, the lower amount of algae did not seem to affect the treatment, such as observed in Sutherland et al. (2014), where different depths were assessed. Considering the aspect of wastewater treatment, we highlight the HRP3, contrary to expectations, as the most efficient pond in terms of organic matter removal, represented by the COD and DOC variables. Since the incidence of radiation is closed connected to the system efficiency in removing pollutants this greater performance was not expected. Oswald (1988) suggests that the maximum load of organic matter applied can be defined from the incident solar radiation, among other parameters. However, such statement can be justified by the greater presence of bacteria (higher TSS and VSS values), which also provided greater nitrification and higher levels of Norg. Moreover, the HRP3 was the only one able to remove CODt and TP, a removal which was also detected in their soluble forms. The phytoplankton activity, reflected in the DO production through photosynthesis, clearly led to nitrification in the ponds, with a 6 -fold increase in the initial nitrate concentration in all HRPs.

\subsection{Composition of the phytoplankton community}

Fig. 3 shows that even though the HRP2 operated with $30 \%$ of blocking, this pond presented the highest mean density of individuals $\left(701,065\right.$ ind $\left.\mathrm{mL}^{-1}\right)$; on the other hand, the HRP3, with $80 \%$ of blocking, presented the lowest mean density of organisms throughout the sampling period $\left(663,167.5\right.$ ind $\left.\mathrm{mL}^{-1}\right)$. Barthel et al. (2008), studying a water hyacinth pond, observed that the hyacinth's shadow rendered the phytoplankton proliferation difficult, and the algae grazing occurrence through the zooplankton, causing lower algae density during all the nine months of monitoring.

The lowest occurrence of phytoplankton organisms was observed in the fall, with a similar behavior to the evolution of solar radiation throughout the year. The greater densities of such organisms were observed in the summer, spring and winter. Larger amounts of phytoplankton organisms in low light seasons are commonly

Table 1

Characterization of the influent sewage and culture medium of the HRPs (mean and standard deviation).

\begin{tabular}{|c|c|c|c|c|}
\hline & UASB & HRP 1 & HRP 2 & HRP 3 \\
\hline CODt (mg/L) & $214.40(105.53)$ & $253.52(174.82)$ & 232.55 (102.39) & $199.6(111.49)$ \\
\hline CODs $(\mathrm{mg} / \mathrm{L})$ & $98.96(24.69)$ & $74.26(30.84)$ & $69.11(30.16)$ & $70.64(30.29)$ \\
\hline $\mathrm{TKN}(\mathrm{mg} / \mathrm{L})$ & $48.35(18.05)$ & $27.32(14.48)$ & $29.5(13.35)$ & $32.33(43.41)$ \\
\hline $\mathrm{N}-\mathrm{NH}_{4}^{+}(\mathrm{mg} / \mathrm{L})$ & $39.82(13.05)$ & $12.43(10.06)$ & $16.35(13.92)$ & $12.11(11.26)$ \\
\hline $\mathrm{N}-\mathrm{NO}_{3}{ }^{-}(\mathrm{mg} / \mathrm{L})$ & $2.58(1.34)$ & $17.09(9.42)$ & $16.05(9.6)$ & $17.19(13.59)$ \\
\hline TSS (mg/L) & $96.03(149.63)$ & $209.23(76.68)$ & $206.13(88)$ & $260.16(180.18)$ \\
\hline VSS (mg/L) & $74.58(98.60)$ & $157.9(54.38)$ & $151.63(58.27)$ & 166.77 (112.65) \\
\hline $\mathrm{DOC}(\mathrm{mg} / \mathrm{L})$ & $41.28(10.33)$ & $18.94(7.36)$ & $18.55(5.22)$ & $16.33(8.8)$ \\
\hline DIC (mg/L) & $47.62(15.63)$ & $14.23(13.49)$ & $18.27(16.73)$ & $11.67(13.81)$ \\
\hline $\mathrm{TP}(\mathrm{mg} / \mathrm{L})$ & $4.95(1.45)$ & $5.22(1.15)$ & $5.25(1.45)$ & $4.89(1.81)$ \\
\hline $\mathrm{SP}(\mathrm{mg} / \mathrm{L})$ & $4.05(1.14)$ & $3.63(1.2)$ & $3.47(1.19)$ & $3.24(1.7)$ \\
\hline Chlorophyll- $a$ (mg/L) & NA & $1.54(\mathrm{a})^{\mathrm{a}}(1.17)$ & $1.59(a)^{a}(0.96)$ & $\begin{array}{l}0.74(b)^{a} \\
(0.56)\end{array}$ \\
\hline VSS/Chlorophyll- $a$ ratio & NA & 186.01 & 165.04 & 383.41 \\
\hline
\end{tabular}

a The $t$-test was performed at the $5 \%$ significance level; means followed by the same letter do not statistically differ. NA=not assessed. 
reported in the literature due to the predation by zooplankton, which preferably develops in the seasons with highest temperatures and light intensities such as the summer (Chang et al., 2014). However, in this study, since the HRPs are located in a hot subtropical climate region, with high temperatures and PAR incidence throughout the year, there was little difference among the seasons.

During the experimental period, we identified 32 genera of phytoplankton in the ponds, with the predominance of the classes Chlorophyceae,Cyanophyceae and Bacillariophyceae (Fig. 4). The blocking of $30 \%$ of the solar radiation (HRP2) allowed for a greater homogeneity of the phytoplankton community, with lower variability throughout the year. On the other hand, the HRP3 presented the highest variation of genera, despite the lower incidence of solar radiation. Jiang et al. (2014) also observed, in a eutrophic lake in China, a greatest number of phytoplankton species in the winter, a period with low solar radiation incidence.

As for HRPs, the main objectives are the production of large amounts of biomass and the sewage treatment, the dominance of one or a few species may be more advantageous than a great variability. We highlight, however, that other aspects such as the lipid content, the sedimentation efficiency, and other characteristics of the dominant species are also important aspects.

The representatives of the class Chlorophyceae showed greater abundance, with the dominance of the genera Chlorella and Desmodesmus. There was a change in the abundance of the genera due to seasonal variations, with an overall tendency towards a larger number of individuals of the genus Desmodesmus in the summer (sampling campaigns 1-4) and fall (campaigns 5-10) and of the genus Chlorella in the winter (campaigns 11-16) and spring (campaigns 17-19), as shown in Fig. 4.

The genera Chlorella and Desmodesmus were more frequent in environments with high organic matter pollution. Barthel et al. (2008) stated that Chlorella sp. was the dominant species during the entire sampling period (February-October) in their HRPs treating piggery waste, located in the south of Brazil. Chlorella cells, highly valued by herbivores due to their small size and spherical shape, are the first cells ingested by predators. However, thanks to its rapid multiplication, the Chlorella can dominate during a less sunny period, when the predator population consists essentially of protozoa. In turn, Desmodesmus cells are consumed after the Chlorella due to its bigger size, the presence of thorns and the formation of colonies. They consist in an excellent source of food for crustaceans, but not for rotifers and protozoa, which allows this genus to dominate in the summer, when the medium is essentially dominated by rotifers (Canovas et al., 1996; Canovas, 1991). de Godos et al. (2010) found a greater diversity of genus in swine manure wastewater: Chlamydomonnas sp., Microspora sp., Clhorella sp., Nitzschia sp., Achananthes sp., Protoderma sp., Senelastrum sp., Oocystis sp., Ankistrodesmus sp., and Chlorella sp., this last one being the only genus also found in our study, despite the different type effluent and geographic location. According to Craggs et al. (2011), HRPs treating domestic sewage are usually dominated by small colonies of genera such as: Scenedesmus, Micractinium, Actinastrum and Pediastrum. Park et al. (2011) stated that the main species found in HRPs treating domestic sewage are Desmodesmus sp., Micractinium sp., Actinastrum sp., Pediastrum sp., Dictyosphaerium sp. and Coelastrum sp.

The diversity of medium conditions observed during the monitoring period, as well as the complexity of the system functioning, resulted in difficult comparisons. However, we can affirm that the solar radiation has not influenced the dominance, but the abundance of the phytoplankton community. In addition, for the conditions assessed in this study, the photoinhibition phenomenon was not observed, since the HRP1 presented a behavior similar to that of the HRP2, which presented $30 \%$ of blocking. Other aspects, such as the competition with other organisms for space and nutrients, may have been more significant for the growth and development of algal biomass. Joseph and Joseph (2002) suggested that factors such as climate, competition and other types of relationships with other organisms, in addition to the production of chemicals by algae, were also responsible for the diversity of species and seasonal variations in the composition of the phytoplankton community observed in the carpet industry effluent. The biological activity of a complex environment dominated by wastewater is probably related to the interactions among its different components, with no substance with a dominant effect (Walsh et al., 1980).

\subsection{Principal components analysis}

The 16 monitored variables were reduced to five principal components (PC) for each pond, which explained $74 \%, 81 \%$ and $78 \%$ of the total variability of the data from HRPs 1,2 and 3, respectively. Fig. 5(a-e) presents the five PCs for each pond.

PC1 explained $26.3 \%, 32.9 \%$ and $31 \%$ of data variability for the HRPs 1, 2 and 3, respectively. This component presented strong contribution of the variables $\mathrm{pH}, \mathrm{SP}, \mathrm{TP}, \mathrm{DIC}, \mathrm{DOC}, \mathrm{N}^{-\mathrm{NO}_{3}}{ }^{-}, \mathrm{N}_{-} \mathrm{NH}_{4}{ }^{+}$ and TKN. Among these variables, both forms of phosphorus were significant in all three ponds, mostly due to the fact that the TP is a constituent of the cells of the microorganisms in the ponds, and the

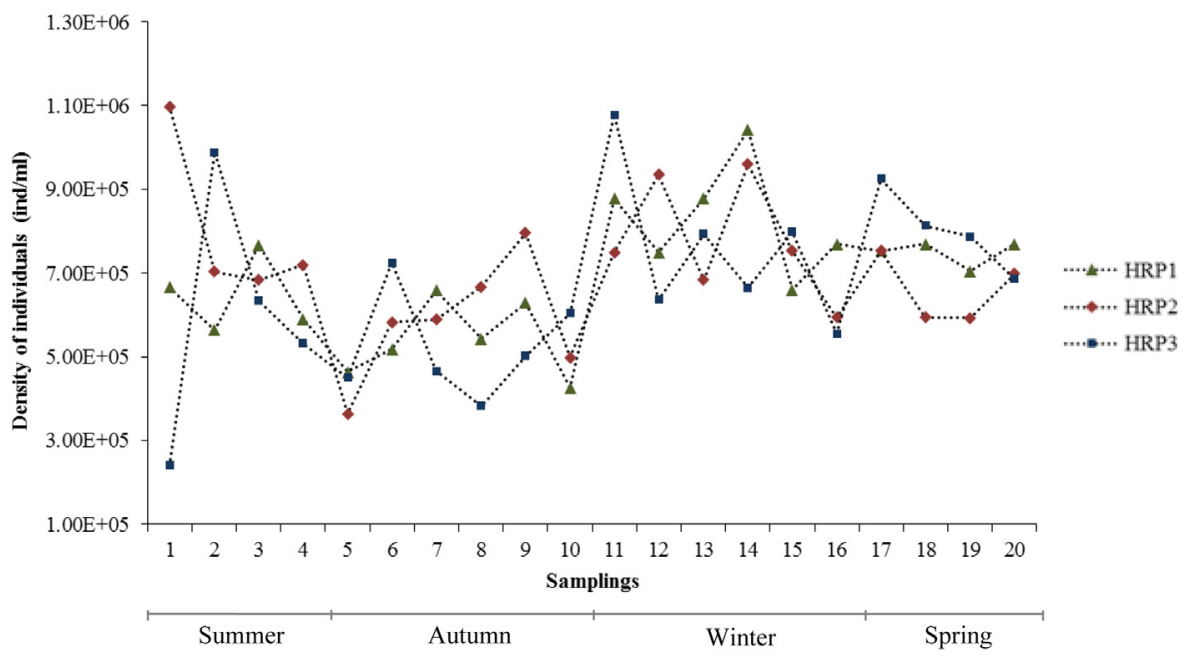

Fig. 3. Density of individuals in the high rate ponds throughout the sampling period. 
SP represents an assimilable source of this nutrient for growth. The DIC and $\mathrm{N}-\mathrm{NH}_{4}{ }^{+}$contributed to the PC1 of the ponds with higher amounts of algal biomass (HRPs 1 and 2), since these variables represent the preferred sources of carbon and nitrogen, respectively, to be assimilated by the algae during their development. The TKN presented strong contribution for the HRPs 1 and 2, possibly because it comprises in its definition the ammonia nitrogen. Another source of carbon is the DOC, which was significant for the HRP2. As discussed in Section 3.2, the phytoplankton community in this pond was dominated by the genus Chlorella, which, depending on the culture medium, can present heterotrophic nutrition using the DOC as a main source of carbon, mostly in periods of absence of solar radiation such as nighttime. The nitrification was the main form of ammonia removal in all ponds,

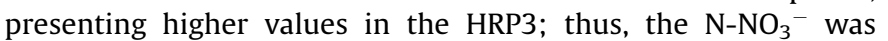
the variable which strongly contributed to the PC1 of the HRP3, the pond with predominance of heterotrophic bacteria.

The PC2 explained $16.8 \%, 17.4 \%$ and $21.5 \%$ of the total variability for the HRPs 1, 2 and 3 respectively. The most important variables

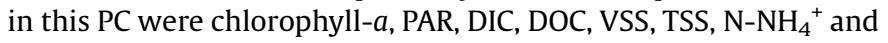
CODt. The larger amount of algal biomass in the HRP2 represented by the higher concentrations of chlorophyll- $a$ was also reflected by the PCA, due to the strong contribution of this variable to the PC2. The PAR also presented strong contribution for this PC, maybe because it reflects an important factor for algal development, reinforcing its influence to the pond with highest amount of algal biomass. The DIC highlighted in the PC1 for the HRPs 1 and 2 was also present in the PC2 for the HRP3. We can infer that its importance is due to the degradation of the organic matter by the bacteria, which is present in larger number in this pond. Similarly, as discussed for DOC in PC1, the importance of this variable in the HRP3 is the heterotrophic nutrition of the bacteria present in majority in this pond. Specifically for the HRP3, the greater limitation of solar radiation allowed for the assimilation of DOC by the heterotrophic algae during the day, i.e., beyond the nighttime

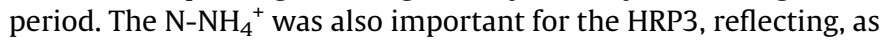
previously discussed (Section 3.2), the greater removal of such variable in this pond. The solids, which indicate both algal and total biomass, were important for the HRP1. Lastly, we highlight the CODt, which contributed to the PC2 of the HRP2, and may indirectly indicate larger amounts of organic matter in this pond, including the contribution of algal biomass.

The PC3 explained $12.7 \%, 14.1 \%$ and $10.6 \%$ of the variability for the HRPs 1, 2 and 3, respectively. This PC was represented by the
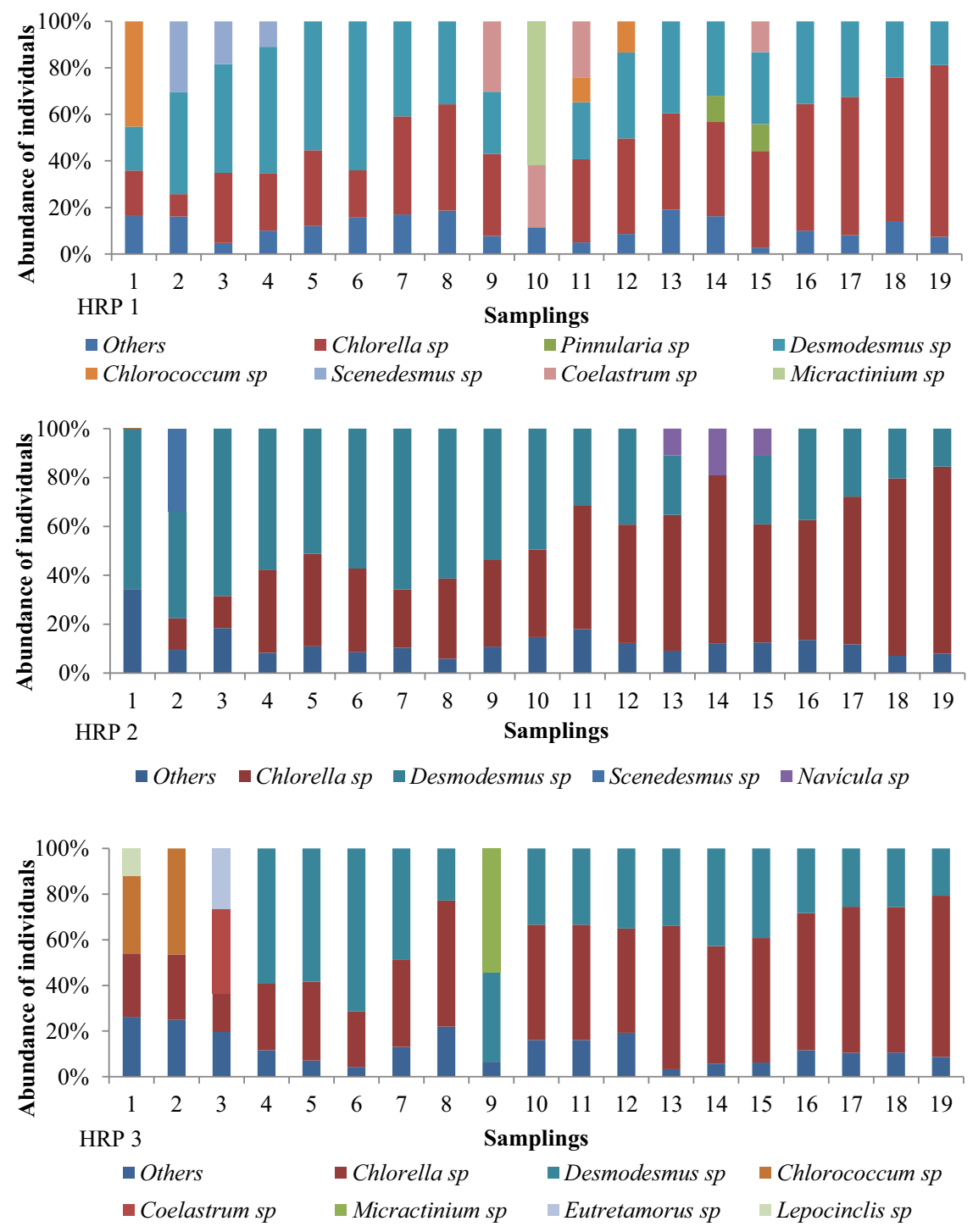

Fig. 4. Variations in the phytoplankton community within the HRPs throughout the sampling periods (abundance of individuals, \%). 
variables $\mathrm{pH}$, PAR, VSS and TSS. The $\mathrm{pH}$ presented negative contribution for the HRP2, indicating the possibility that high levels of $\mathrm{pH}$ can be harmful to the development of microorganisms in this pond, represented by the importance of the TSS and VSS variables for this pond as well. The PAR, as previously mentioned for the HRP2 in the PC2, may reflect an important factor for algal development in the HRP1.

The PCs 4 and 5 presented lower contributions to explain the total variability in the data. The PC4 was responsible for explaining $11.0 \%, 10.2 \%$ and $8.8 \%$, whereas PC5 explained $7.9 \%, 6.8 \%$ and $6.4 \%$ of the total variability in data from the HRPs 1,2 and 3, respectively. In the PC4, we highlight the chlorophyll- $a$ for the HRP3 and the negative contribution of the DO for the HRP1. In the PC5, the CODs was significant for the HRP2.

\subsection{Linear multiple regression}

All model coefficients were statistically significant at the 5\% significance level, with the exception of TSS in the HRP1 (10\%). The positive influence indicates that the higher the concentration of the variable in the pond, the larger the total number of individuals, whereas the negative influence accounts for a reduction in the number of individuals with the increase in the concentration of such variable.
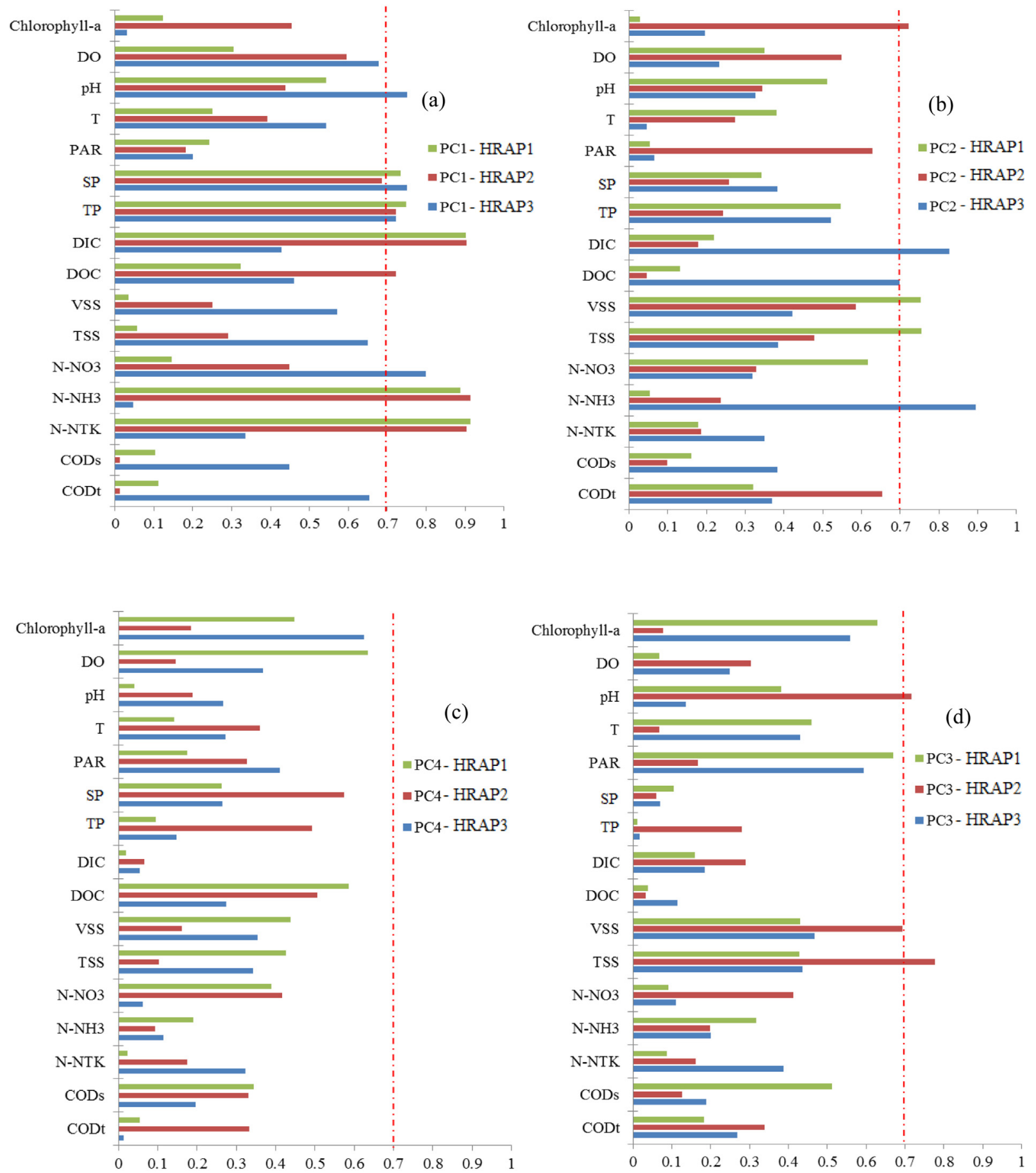

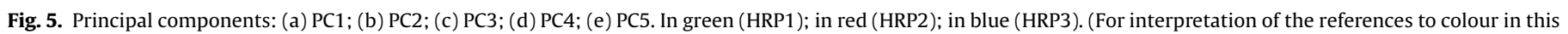
figure legend, the reader is referred to the web version of this article.) 
Table 2

Results of the multiple regression analysis for the HRPs 1, 2 and 3 (total phytoplankton biomass is the independent variable).

\begin{tabular}{|c|c|c|c|c|}
\hline \multicolumn{5}{|c|}{ Phytoplankton biomass $(\mathrm{HRP} 1)=15813[\mathrm{CID}]+1285[\mathrm{SST}]-17,797[\mathrm{TKN}]+361554 R^{2}$ adjust $=0.4098$} \\
\hline Parameters & Coefficients & SD & $t$ value & Probability \\
\hline DIC & 15813 & 6870 & 2.302 & 0.0401 \\
\hline SP & 87171 & 33959 & 2.567 & 0.0247 \\
\hline TKN & -17797 & 6769 & -2.629 & 0.022 \\
\hline TSS & 1285 & 707 & 1.818 & 0.0941 \\
\hline Constant & 361554 & & & \\
\hline \multicolumn{5}{|c|}{ Phytoplankton biomass $(\mathrm{HRP} 2)=69932\left[\right.$ chlorophyll-a] $-3848[\mathrm{CODs}]+84995 R^{2}$ adjust $=0.493$} \\
\hline Parameters & Coefficients & $\mathrm{SD}$ & $t$ value & Probability \\
\hline CODs & -3848 & 1146 & -3.357 & 0.0064 \\
\hline Chlorophyll-a & 69932 & 30233 & 2.313 & 0.0411 \\
\hline Constant & 849995 & & & \\
\hline \multicolumn{5}{|c|}{ Phytoplankton biomass $(\mathrm{HRP} 3)=78927[\mathrm{Pt}]+241755 R^{2}$ adjust $=0.4107$} \\
\hline Parameters & Coefficients & SD & $t$ value & Probability \\
\hline TP & 78927 & 23319 & 3.385 & 0.00445 \\
\hline Constant & 241755 & & & \\
\hline
\end{tabular}

The results reinforce that the primary productivity is increased by a combination of factors, instead of a single one. Similar to the results presented by Nicklisch et al. (2008) and Mahmoudi et al. (2014), for the HRPs 1 and 2 assessed in the present study, the phytoplankton growth was not limited by only one variable at a time, but the limitation caused by one variable was capable of changing the demand for others.

Table 2 presents the regression equations for each pond.

The determination coefficient of the linear multiple regression $\left(R^{2}\right.$ adjust. $)$ for the HRP1 was 0.4098 , which means that $40.98 \%$ of the total variability in the phytoplankton population can be explained by the variables DIC, SP and TSS, that positively influenced the phytoplankton population, and by the TKN, which presented negative influence. The limiting effect of TKN in the phytoplankton density can be related to the rapid assimilation of this variable, more specifically the assimilation of the $\mathrm{N}^{-\mathrm{NH}_{4}}{ }^{+}$fraction, leading to lower concentrations of this variable in the pond (as shown in Table 2). The same limiting behavior was observed by Mahmoudi et al. (2014) for the $\mathrm{N}^{-\mathrm{NO}_{3}}{ }^{-}$. The variable $\mathrm{N}-\mathrm{NH}_{4}{ }^{+}$also played an important role in the primary productivity in the San Francisco Bay USA. According to Dugdale et al. (2007), anthropogenic sources of $\mathrm{N}-\mathrm{NH}_{4}{ }^{+}$, if not sufficiently diluted, may prevent the formation of phytoplankton blooms, since they can limit their access to nitrate. The TSS coefficient was low, if compared with the coefficients for the other variables, which shows that small changes in its value do not significantly affect the amount of phytoplankton and indicate that in this pond, the competition between algae and bacteria did not represent a factor of great relevance.

For the HRP2, the $R^{2}$ adjust. was 0.4903 , which means that $49.03 \%$ of the variability in the phytoplankton population can be positively explained by the variable chlorophyll- $a$, and negatively by the variable CODs. The variable chlorophyll- $a$ directly expresses the algal biomass, mostly the class Chlorophyceae, which was more abundant in the studied ponds. The HRP2 was also the one that presented the highest chlorophyll- $a$ values, indicating the importance of this variable in the prediction of the phytoplankton biomass. These results are corroborated by Luo et al. (2009), who describe the chlorophyll analysis as the most acceptable method for studying biological production. The CODs was inversely proportional to the phytoplankton biomass. Mahmoudi et al. (2014) reported that the accumulation of organic matter can cause the reduction in the penetration of oxygen into sediments in water bodies, leading to a decrease in the primary productivity based on nitrification during the spring and winter.

For the HRP3, it was not possible to obtain multiple variables with a good significance level for the coefficients, resulting in a simple regression which explained $41.07 \%$ of the variability in the data. This result can be explained by the lower presence of phytoplankton organisms in this pond, reflected by the lower chlorophyll- $a$ values and number of individuals per $\mathrm{mL}$, and the greater dominance of bacteria over algal biomass, shown by the high VSS/chlorophyll- $a$ ratio. The regression pointed out that the TP in the pond acts positively as the best indicator of the presence of phytoplankton biomass. This is due to the fact that, many times, the amount of phosphorus in a water body is a limiting factor for the growth of organisms, from the nutritional point of view. Thus, the higher the amount of TP, the larger the number of phytoplankton organisms in the HRP3, which is an environment limited by the low incidence of solar radiation.

Given that for an HRP, the greater the phytoplankton productivity, the better the obtention of larger amounts of biomass for processing and generating bioenergy, we can state that the regression models indicate how to maximize this production in every tested condition. However, when using wastewater as culture medium, we can affirm that the production of any amount of biomass is welcome, keeping in mind that the algal biomass is richer in lipid content than bacteria, which is, in turn, of easier settleability and easier anaerobic degradability for biogas generation. Therefore, we highlight that the performance of the three HRPs can be considered more or less suitable depending on the final use intended for the biomass.

\section{Conclusions}

A total of 32 genera of phytoplankton were identified in the ponds, and the class Chlorophyceae was the most abundant during the entire period, with larger number of individuals of the genus Desmodesmus in the summer and fall, and the genus Chlorella in the winter and spring. The lower occurrence of phytoplankton organisms was observed in the fall, with a behavior similar to that of the solar radiation throughout the year. Blocking $30 \%$ of the radiation allowed for a lower variability in the community and favored the growth of biomass with greater density of individuals, and higher chlorophyll- $a$ and DO concentrations. On the other hand, the HRP3, with $80 \%$ of radiation blocking, was the pond with the lowest mean density of organisms, which, from the viewpoint of wastewater treatment, can be considered as the most efficient pond in terms of organic matter and nutrient removal.

For the conditions assessed in this study, the photoinhibition phenomenon was not observed. Other aspects such as competition with other microorganisms for space and nutrients, and predation 
by zooplankton, seemed to be more significant for the growth and development of algal biomass.

According to the regression analysis, the algal biomass in HRPs can be maximized mostly taking into consideration the positive effects of carbon and phosphorus, and the limiting effect of nitrogen and non-biodegradable organic load. The shading conditions tested in this study may serve to simulate environments under different climatic conditions and light intensities.

\section{Acknowledgments}

This work was financially supported by the National Council for Scientific and Technological Development, CNPq, the Research Support Foundation of Minas Gerais, FAPEMIG and the Minas Gerais State/SECTES (Secretaria de Estado de Ciência, Tecnologia e Ensino Superior).

\section{References}

American Public Health Association (APHA), 2005. Standard Methods for the Examination of Water and Wastewater, 21st ed. APHA-AWWA-WEF, Washington, DC.

Balachandran, K.K.K., Jayalakshmy, V., Laluraj, C.M., Nair, M., Joseph, T., Sheeba, P., 2008. Step up multiple regression model to compute chlorophyll- $a$ in the coastal waters off Cochin: southwest coast of India. Environ. Monit. Assess. 139, 217-226.

Barthel, L., Armando, P., Oliveira, V., Helena, R., 2008. Plankton biomass in secondary ponds treating piggery waste. Braz. Arch. Biol. Technol. 51, 1287-1298.

Bicudo, C.E.M., Menezes, M., 2006. Gêneros de Algas de Águas Continentais do Brasil (chave Para Identificação e Descrições), 2a edição RiMa, São Carlos [in Portugese].

Bourrelly, P., 1970. Les alges d'eau douce. Initiation à la sistematique. III Les algues blues et rouges. Les Eugléniens, Peridiniens et Cryptomonadines. Nouvelle Boubée \& Cie, Paris [in French].

Canovas, S., 1991. Structure Du Zooplankton En Traitement Des Eaux Uses Par Lagunage a Haut Rendement. Montpellier University I, France, pp. 170 Doctoral Thesis [in French].

Canovas, S., Picot, B., Casellas, C., Zulkifi, H., Dubois, A., Bontoux, J., 1996. Seasonal development of phytoplanktn and zooplankton in a high-rate algal pond. Water Sci. Technol. 33 (7), 199-206.

Chang, C.W., Shiah, F.K., Wu, J.T., Miki, T., Hsieh, C., 2014. The role of food availability and phytoplankton community dynamics in the seasonal succession of zooplankton community in a subtropical reservoir. Limnologica 46, 131-138.

Chisti, Y., 2007. Biodiesel from microalgae. Biotechnol. Adv. 25, 294-306.

Craggs, R.J., Heubeck, S., Lundquist, T.J., Benemann, J.R., 2011. Algae biofuel from wastewater treatment high rate algal ponds. Water Sci. Technol. 63, 660-665.

Cromar, N.J., Fallowfield, H.J., Martin, N.J., 1996. Influence of environmental parameters on biomass production and nutrient removal in high rate algal pond operated by continuous culture. Water Sci. Technol. 34, 133-140.

Development Core Team R, 2013. R: A Language and Environment for Statistical Computing. Foundation of Statistical Computing, Vienna.

Dugdale, R.C., Wilkerson, F.P., Hogue, V.E., Marchi, A., 2007. The role of ammonium and nitrate in spring bloom development in San Francisco Bay. Estuarine Coastal Shelf Sci. 73, 17-29.

Fernandes, B.D., Mota, A., Ferreira, A., Dragone, G., Teixeira, J.A., Vicente, A.A., 2014. Characterization of split cylinder airlift photobioreactors for efficient microalgae cultivation. Chem. Eng. Sci. 117, 445-454. de Godos, I., Blanco, S., Gárcis-Encina, P.A., Becares, E., Muñoz, R., 2010. Influence of flue gas sparging on the performance of high rate algae ponds treating agroindustrial wastewaters. J. Hazard. Mater. 179, 1049-1054.

Horne, A.J., Goldman, C.R., 1994. Limnology, second ed. McGraw Hill, Inc., New York.

Huang, J., Ho, M., Du, P., 2011. Assessment of temporal and spatial variation of coastal water quality and source identification along Macau peninsula. Stoch. Env. Res. Risk Assess. 25, 353-361.

Jiang, Y.J., He, W., Liu, W.X., Qin, N., Ouyang, H.L., Wang, Q.M., Komg, X.Z., He, Q.S. Yang, C., Yang, B., Xu, F.L., 2014. The seasonal and spatial variations of phytoplankton community and their correlation with environmental factors in a large eutrophic Chinese lake (Lake Chaohu). Ecol. Indic. 40, 58-67.

Joseph, V., Joseph, A., 2002. Ecology and seasonal variation of microalgal community in an oil refinery effluent holding pond: monitoring and assessment. Environ. Monit. Assess. 80, 175-185.

Luo, H., Liu, D., Ji, D., Huang, Y., Huang, Y., 2009. Influence factors analysis to chlorophyll-a of spring algal bloom in Xiangxi bay of three Gorges reservoir. J. Water Resour. Prot. 3, 188-194.

Mahmoudi, N., Ahmadi, M.R., Babanezhad, M., Seyfabadi, J., 2014. 2014. Environmental variables and their interaction effects on chlorophyll-a in coastal waters of the southern Caspian Sea: assessment by multiple regression grey models. Aquat. Ecol. doi:http://dx.doi.org/10.1007/s10452-014-9489-9.

Nederlands Norm (NEN), 1981. NEN 6520. Water: Spectrophotometric Determination of Chlorophyll a Content. Nederlands Normalisatie-Instituut, Delft, The Netherlands [in Dutch].

Nicklisch, A., Shatwell, T., Kohler, J., 2008. Analysis and modelling of the interactive effects of temperature and light on phytoplankton growth and relevance for the spring bloom. J. Plankton Res. 30, 79-91.

Parra, O.O., González, M., Dellarosa, V., 1983. Manual Taxonômico del Fitoplancton de água continentales. V- Chlorophyceae. Concepcion, Chile, pp. 151.

Oswald, W.J., 1988. Micro-algae and waste-water treatment. In: Borowitzka, M.A., Borowitzka, L.J. (Eds.), Micro-Algal Biotechnology. Cambridge University Press, Cambridge, pp. 305-328.

Oswald, W.J., Golueke, C., 1960. Biological transformation of solar energy. Adv. Appl Microbiol. 2, 223-262.

Park, J.B.K., Craggs, R.J., 2011. Nutrient removal in wastewater treatment high rate algal ponds with carbon dioxide addition. Water Sci. Technol. 63 (8), 1758-1764.

Park, J.B.K., Craggs, R.J., Shilton, A.N., 2011. Recycling algae to improve species control and harvest efficiency form a high rate algal pond. Water Res. 45 , 6637-6649.

Pires, J.C.M., Alvim-Ferraz, M.C.M., Martins, F.G., Simões, M., 2013. Wastewater treatment to enhance the economic viability of microalgae culture. Environ. Sci. Pollut. Res. Int. 20, 5096-5105.

Santiago, A.F., Calijuri, M.L., Assemany, P.P., Calijuri, M.C., Reis, A.J.D., 2013. Algal biomass production and wastewater treatment in high rate algal ponds receiving disinfected effluent. Environ. Technol. 34, 1877-1885.

Sutherland, D.L., Turnbull, M.H., Craggs, R.J., 2014. Increased pond depth improve algal productivity and nutriente removal in wastewater treatment high rate algal ponds. Water Res. 53, 271-281.

Thangaradjou, T., Sethubathi, G.V., Raja, S., Poornima, D., Shanthi, R. Balasubramanian, T, Babu, K.N., Shukla, A.K., 2012. Influence of environmental variables on phytoplankton floristic pattern along the shallow coasts of southwest Bay of Bengal. Algal Res. 1, 143-154.

Yuan, Z., Blackall, L.L., 2002. Sludge population optimization: a new dimension for the control of biological wastewater treatment systems. Water Res. 36, 4882-4890.

Walsh, G.E., Bahner, L.H., Horning, W.B., 1980. Toxicity of textile mill effluents to freshwater and estuarine algae: crustaceans and fishes. Environ. Pollut. (Ser. A) 21, 169-179.

Wium-Andersen, T., Nielsen, A.H., Hvitved-Jacobsen Brix, H., Arias, C.A., Vollertsen, J., 2013. Modeling the eutrophication of two mature planted stormwater ponds for runoff control. Ecol. Eng. 61, 601-613. 